\title{
A STUDY OF ADJUVANT CHEMORADIOTHERAPY IN RESECTED GASTRIC CANCERS
}

\author{
Chatharaju Swarna Kumari ${ }^{1}$, Ranganatharao Srikanth ${ }^{2}$ \\ 1 Junior Resident, Department Radiotherapy, MNJIO \& RCC, Hyderabad. \\ ${ }^{2}$ Assistant Professor, Department Radiotherapy, MNJIO \& RCC, Hyderabad.
}

\section{ABSTRACT}

\section{AIM AND OBJECTIVES}

To evaluate the effect of addition of adjuvant radiation to adjuvant chemotherapy in resected gastric cancer patients in terms of benefit and toxicity profile.

\section{MATERIALS AND METHODS}

MNJIO\&RCC, Hyderabad is a tertiary care cancer hospital which caters to the cancer patients of Andhra Pradesh and its neighbouring states with a patient load of around 10,000 per year. Thirty Patients were recruited and were treated with concurrent chemotherapy of Inj. 5-FU and Inj. LV for first 3 days and last three days of radiation and two more cycles were given after 4 weeks of radiation at one month gap. Radiotherapy was delivered using Telecobalt unit of 45 Gy in 25 fractions to stomach bed after shielding left kidney after 19.8 Gy.

\section{RESULTS}

Our prospective study consisted of 30 patients, 25 were male and 5 were female. The mean age was 45 years (range 25-71), and the median age was 46 years. 27 patients (90\%) had a performance status of ECOG PS of 0 or 1, 3 patients had ECOG PS-2. Fourteen (14) patients (45\%) underwent distal gastrectomy, 10 patients (35\%) underwent subtotal gastrectomy, and 6 patients (20\%) underwent total gastrectomy. Of the 30 patients, 14 patients (45\%) had D1-LN dissection and 16 patients (55\%) had D2-LN dissection. Five (5) patients were stage IB, 8 patients (30\%) were stage - IIB, 12 patients (40\%) were stage-IIIA and 5 patients (15\%) were stage IIIB. The full course according to protocol was completed by 28 patients $(95 \%)$ and 2 patients had interruption in treatment because of grade-3 gastrointestinal toxicity. Acute toxicity as shown below was recorded during the entire course of treatment. The most common acute toxicity observed was vomiting in 19 patients (65\%) followed by grade- 1 mucositis in 18 patients $(60 \%)$ and grade-1 neutropenia in 18 patients (60\%). The median followup was 12 months and mean followup was 16 months. Among 28 patients who completed the treatment, 8 patients (28\%) had recurrences during followup period (documented by endoscopy \& ultrasound). 7 patients (25\%) had locoregional recurrence and 1 patient (3.6\%) developed liver metastasis. The median time to relapse from the end of the radiation was 11 months. The locoregional control rates were (71\%) 20/28 patients. Based on the observations above mentioned, the relapses were observed in patients with stage IIIA\&B, poorly differentiated adenocarcin omas. In 8 patients who experienced relapses, 5 patients had D1-LN dissection and 3 patients had D2-LN dissection. These results were compared with 30 patients of carcinoma stomach who underwent curative resection and received only adjuvant chemotherapy of Inj. 5-FU and leucovorin and kept on followup from our institute with similar tumour patient characteristics as study group, 15/30 patients (50\%) relapsed locoregionally and 3/30 (10\%) relapsed distantly. All the patients who relapsed during followup period had D2 lymph node dissection and mostly were stage III and IV.

\section{CONCLUSION}

Addition of radiation to adjuvant 5-FU and Leucovorin chemotherapy has shown definite benefits in the form of reduced recurrences for all patients with high risk gastric cancer who underwent curative surgery. The toxicity profile was acceptable and manageable.

\section{KEYWORDS}

Gastric Cancers, Adjuvant Chemoradiotherapy, Survival Benefits, Toxicity.

HOW TO CITE THIS ARTICLE: Kumari CS, Srikanth R. A study of adjuvant chemoradiotherapy in resected gastric cancers. J. Evolution Med. Dent. Sci. 2016;5(78):5791-5795, DOI: 10.14260/jemds/2016/1307

\section{INTRODUCTION}

Non-communicable diseases including cancer are emerging as a major health problem in India. Globally, the burden of new cancer cases in the year 2000 was estimated to be around 10 million with more than half originating from the developing

Financial or Other, Competing Interest: None.

Submission 06-09-2016, Peer Review 19-09-2016,

Acceptance 21-09-2016, Published 28-09-2016.

Corresponding Author:

Dr. Chatharaju Swarna Kumari,

Consultant, Basavatarakam Indo-American Cancer Institute,

Banjara Hills, Road No. 12,

Hyderabad.

E-mail:dr.swarnakumari@yahoo.com

DOI: $10.14260 /$ jemds/2016/1307 world population. ${ }^{1}$ Gastric cancer is the fourth most common malignancy in the world after the lung, breast and colorectal malignancies. ${ }^{2}$ and second leading cause of cancer related deaths in the world in both sexes. ${ }^{3,4}$ In India, the AAR (Age Adjusted Rates) of gastric cancer in the urban registries (3.013.2) are on the lower side among those reported worldwide (4.1-95.5). It is a disease mainly of males, $\mathrm{M}: \mathrm{F}=2: 1$. It occurs a decade earlier among south Indians compared to north Indians ${ }^{5}$ and the incidence is 4 times higher in south India than north. ${ }^{6}$ MNJIO\&RCC, Hyderabad is a tertiary care cancer hospital which caters to the cancer patients of Telangana \& Andhra Pradesh and its neighbouring states with a patient load of around 10,000 per year. Stomach cancer is one of the common GI cancers at our institution. 
The annual incidence rate ranges from 3.060 to $4.02 \%$. The average male to female ratio is 2.47:1. Consumption of red chillies, food at very high temperatures and alcohol are the main risk factors for stomach cancers in India. ${ }^{7}$ The only proven curative treatment for gastric cancer is surgical resection of all gross and microscopic disease. ${ }^{8}$ Nevertheless, studies have shown that surgery alone is less than satisfactory with the 5-year survival rate is as low as 10-20\%.9 except in Japan where 5 -year survival is $40-45 \%$. Even after what is felt to be a curative gastrectomy. ${ }^{9}$, disease recurs in both regional and distant sites in the majority of patients. In Japan and Korea where gastric cancer is endemic, radical gastrectomy with D2 lymphadenectomy or higher has been regarded as standard of surgery, although survival advantage is not confirmed in randomised trials. However, in Japan and Korea, distant organs and peritoneum (43\%) were the main sites of recurrence. Yoo et $\mathrm{al}^{10}$ reported $46 \%$ of peritoneal recurrence in gastric cancer patients receiving D2 lymph node dissection in Japan. The frequency of such relapses made adjuvant therapy with chemotherapy an attractive strategy to improve local control rates and decrease distant failures in resected gastric cancer patients, but meta-analysis from several randomised trials failed to demonstrate significant improvement in survival with the use of post-operative chemotherapy alone in resected gastric cancer patients.

Addition of post-operative radiotherapy to chemotherapy has shown definite improvement in disease control rates (ref MacDonald etal ${ }^{11}$ in the results of GI INT 0116 trial comparing the effects of postoperative chemoradiotherapy with surgery alone). Surgery is the main modality of treatment practised in India; however, extensive lymph node dissection is not practised as regularly as in Japan. Curative surgery is performed in about $20 \%$ of the cases. The 5 years overall survival in India ranges from $5 \%$ to $18 \%$ which is almost similar to that in western countries. With this background, the aim of the present study is to determine the efficacy of addition of Radiotherapy to Adjuvant Chemotherapy in resected gastric cancer patients in our institute.

\section{MATERIALS AND METHODS}

Gastric cancer is one of the common GI cancers at our institution. The annual incidence rate ranges from 3.060 to $4.02 \%$. The average male to female ratio is $2.47: 1$. In our prospective study, we have included 30 patients registered at MNJIO\&RCC with confirmed diagnosis of adenocarcinomas of stomach, post-operative cases with the intention of curative resection. Study period is from September 2008 to September 2010.

\section{Inclusion Criteria}

Age should be less than 75 years, histopathologically confirmed adenocarcinoma of the stomach, ECOG PS 0,1,2, resected gastric cancer with $\mathrm{R} 0$ resection, with no $\mathrm{H} / \mathrm{O}$ other malignancies, no $\mathrm{H} / \mathrm{O}$ previous evidence of treatment such as chemotherapy or radiotherapy, CA stomach AJCC stage IB-III with M0 status, adequate function of major organs confirmed by WBC $>4000 /$ cu.mm, PC>15000/cu.mm, HB\% >10 g\%, serum creatinine $<1.5 \mathrm{mg} / \mathrm{dL}$, LFT - WNL, no comorbid illness such as heart, renal, hepatic failures and uncontrolled infections, informed consent.

\section{Exclusion Criteria}

Age more than 75 years, ECOG PS 3 or more, any evidence of distant metastasis, comorbid conditions like hypertension, COPD, cirrhosis, defaulted patients, Haematological parameters like WBC $<4000 /$ cu.mm, PC $<15000 /$ cu.mm, Serum creatinine $>1.5 \mathrm{mg} / \mathrm{cu} . \mathrm{mm}$, palliative resection of stomach cancer, histologies other than adenocarcinomas.

\section{Pre-Treatment Evaluation}

Complete history and physical examination including for distant sites of disease like hepatomegaly or supraclavicular nodes, $\mathrm{P} / \mathrm{V}$ (for any adnexal masses) in female patients, $\mathrm{P} / \mathrm{R}$ (for deposits in POD).

Haematological, Radiological investigations including U/S Scan of abdomen and CT Scans of abdomen \&/or chest and Model postop histopathology report.

Protocol Design.

Resected stage I-III (M0) (87\% with positive lymph nodes). Adenocarcinomas of the stomach.

\section{Protocol Design}

\begin{tabular}{|c|c|c|c|}
\hline $\begin{array}{c}\text { Day } 1 \\
\text { to } \\
\text { Day } 5\end{array}$ & \multicolumn{2}{|c|}{ After 4 weeks } & After 4 weeks \\
\hline \multirow{2}{*}{$\begin{array}{l}\text { I cycle } \\
\text { chemo } \\
\text { Inj. 5- } \\
\text { FU } 425 \\
\mathrm{mg} / \mathrm{m}^{2} \\
\text { Inj. LV } \\
20 \\
\mathrm{mg} / \mathrm{m}^{2}\end{array}$} & \multicolumn{2}{|c|}{$\begin{array}{l}\text { EBRT to tumour bed of } 45 \\
\text { Gy/25 fractions by } \\
\text { Telecobalt unit by AP-PA } \\
\text { fields in conventional } \\
\text { fractions of } 180 \text { cGy per } \\
\text { fraction, five } \\
\text { fractions/week with left } \\
\text { kidney shielding after } 19.8 \\
\text { Gy }\end{array}$} & \multirow{2}{*}{ 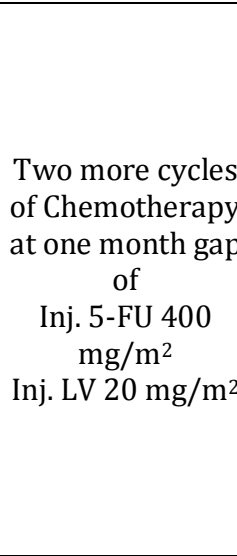 } \\
\hline & $\begin{array}{c}\text { On Days } 1 \\
\text { to } 4 \text { of RT } \\
\text { Inj. } 5-\mathrm{FU} \\
400 \mathrm{mg} / \mathrm{m}^{2} \\
\text { Inj. } \mathrm{LV} 20 \\
\mathrm{mg} / \mathrm{m}^{2}\end{array}$ & $\begin{array}{c}\text { On days } 23 \\
\text { to } 25 \text { of RT } \\
\text { Inj. } 5-\mathrm{FU} \\
400 \mathrm{mg} / \mathrm{m}^{2} \\
\text { Inj. } \mathrm{LV} 20 \\
\mathrm{mg} / \mathrm{m}^{2}\end{array}$ & \\
\hline
\end{tabular}

Inj. 5-Fluorouracil was given as infusion with normal saline over 3 hours and Inj. Leucovorin was administered as bolus.

\section{Followup}

After completion of the treatment, regular followup was done. Every 2 months for 6 months.

Every 3 months for 2 years.

In each followup visit,

- History for any symptoms.

- Complete physical examination.

- UGI endoscopy every 3 months.

- Ultrasound abdomen \& Pelvis every 3 months.

- Chest X-ray every 3 months.

- CT scan abdomen \& pelvis if any significant symptoms or every 6 months regularly.

In our study, patients had a minimum followup of 2 months and maximum followup of 22 months, Median followup - 12 months. Patients were evaluated for treatment related toxicity, local recurrences and distant metastasis. 


\section{RESULTS}

A prospective study of 30 patients with adenocarcinomas of the stomach (Postop), following strict selection criteria as outlined previously was done. The patients were treated with adjuvant concurrent chemoradiation as per the protocol mentioned previously. Informed consent was taken after explaining in detail the treatment benefits \& risks. Emphasis was laid on documenting the toxicity of the treatment \& nutritional status of the patients during treatment.

\begin{tabular}{|c|c|}
\hline Age Group & No. of Patients \\
\hline $20-29$ & 1 \\
\hline $30-39$ & 4 \\
\hline $40-49$ & 10 \\
\hline $50-59$ & 10 \\
\hline $60-69$ & 3 \\
\hline $70-79$ & 2 \\
\hline Sex & 25 \\
\hline Male & 5 \\
\hline Female & 7 \\
\hline Location & 6 \\
\hline Proximal & 17 \\
\hline Body & \\
\hline Antrum & \\
\hline \multicolumn{2}{|c|}{ Table 1: Demographic Distribution } \\
\hline \multicolumn{2}{|c}{} \\
\hline
\end{tabular}

\begin{tabular}{|c|c|}
\hline T-Stage & No. of Patients \\
\hline T2 & 12 \\
\hline T3 & 12 \\
\hline T4 & 6 \\
\hline N-stage & 4 \\
\hline N0 & 16 \\
\hline N2 & 8 \\
\hline N3 & 2 \\
\hline Stage & 2 \\
\hline IB & 9 \\
\hline II & 12 \\
\hline IIIA & 4 \\
\hline III & 3 \\
\hline Table 2: Shows T-stage, $\boldsymbol{N}$-stage, Stage \\
\hline
\end{tabular}

\begin{tabular}{|c|c|}
\hline Grade & No. of Patients \\
\hline 1 & 3 \\
\hline 2 & 17 \\
\hline 3 & 10 \\
\hline \multicolumn{2}{|l|}{ LN dissection } \\
\hline D1 & 14 \\
\hline D2 & 16 \\
\hline \multicolumn{2}{|l|}{ Surgery } \\
\hline Total gastrectomy & 6 \\
\hline Distal/subtotal gastrectomy & 24 \\
\hline Table 3: Shows Grade, LN Disse & Type of Surgery \\
\hline
\end{tabular}

Our prospective study consisted of 30 patients, 25 were male and 5 were female. The mean age was 45 years (range 25-71), and the median age was 46 years. 27 patients (95\%) had a performance status by ECOG of 0 or 1,3 patients had ECOG PS-2. 14 patients (45\%) underwent distal gastrectomy, 10 patients (35\%) underwent subtotal gastrectomy, 6 patients (20\%) underwent total gastrectomy. Of 30 patients, 14 patients (45\%) had D1-LN dissection and 16 patients (55\%) had D2-LN dissection. 5 patients were stage IB, 8 patients
(30\%) were stage - II, 12 patients (40\%) were stage-IIIA and 5 patients $(15 \%)$ were stage IIIB\&C. The full course according to protocol of concurrent chemoradiotherapy and two cycles of chemotherapy of thirteen weeks was completed by 28 patients (95\%) (Table 1) and 2 patients had interruption in treatment because of grade- 3 gastrointestinal toxicity. Acute toxicity as described below was recorded during concurrent chemo irradiation.

The most common acute toxicity observed was Grade 1 vomiting in 19 patients (65\%) followed by grade- 1 mucositis in 18 patients $(60 \%)$ and grade- 1 neutropenia in 18 patients (60\%). (Table 3)

The median followup was 12 months and mean followup was 16 months. Among 28 patients who completed the treatment, 8 patients $(26.3 \%)$ relapsed during followup period (documented by endoscopy \& ultrasound). 7 patients (21\%) had locoregional recurrence and 1 patient (5.2\%) relapsed distantly (liver). The median time to relapse from the end of the radiation was 11 months. The locoregional control rates were $(71 \%)$ 20/28 patients. Based on the above-mentioned observations, the relapses were observed in patients with stage III, poorly differentiated adenocarcinomas. In 8 patients who experienced relapse, all patients had local lymph node metastasis (3 in D1 dissection and 5 in D2 dissections).

The incidence of late toxicities like radiation nephropathy or hepatotoxicity was not evident in any of the patients followed.

These results were compared with 30 patients of carcinoma stomach who underwent curative resection and kept on followup from our institute with similar tumour patient characteristics as study group (Table 2.), 15/30 patients (50\%) relapsed locoregionally and 3/30 (10\%) relapsed distantly. All the patients who relapsed during followup period had D2 lymph node dissection were stage III. The results show better survival with chemo irradiation than chemotherapy alone, though the findings were not analysed for statistical significance.

\section{Results at 12 Months of Median followup}

\begin{tabular}{|c|c|c|c|}
\hline $\begin{array}{c}\text { Total } \\
\text { Cases } \\
\text { Followed }\end{array}$ & $\begin{array}{c}\text { Disease } \\
\text { Free }\end{array}$ & Relapses & $\begin{array}{c}\text { Sites } \\
\text { of Relapses }\end{array}$ \\
\hline $28(95 \%)$ & $20(71 \%)$ & $8(29 \%)$ & $\begin{array}{c}7- \\
\text { locoregional }\end{array}$ \\
\cline { 3 - 4 } & & $1--$ liver \\
\hline
\end{tabular}

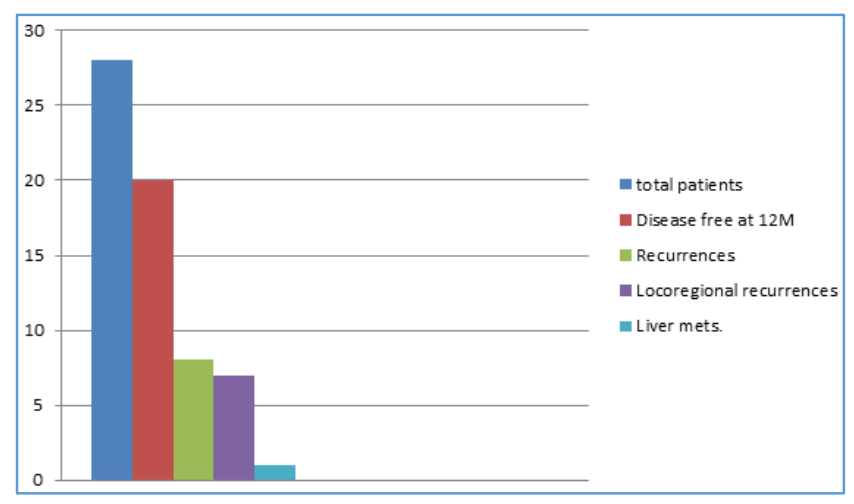

Fig. 1: Study ARM 


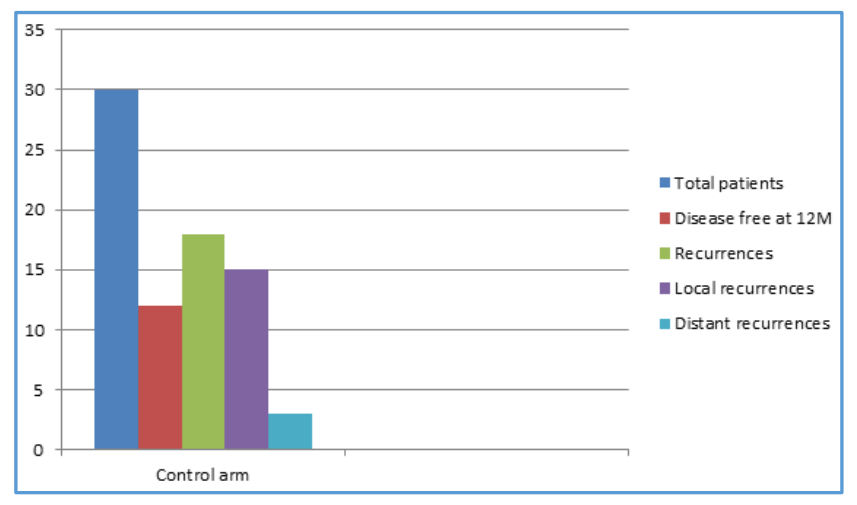

Fig. 2: Control ARM

Toxicity Profile

\begin{tabular}{|c|c|c|}
\hline Type & Number & Percentage \\
\hline Vomiting Grade 1 & 19 & $65 \%$ \\
\hline Grade 1 mucositis & 18 & $60 \%$ \\
\hline Grade 1 Neutropenia & 18 & $60 \%$ \\
\hline
\end{tabular}

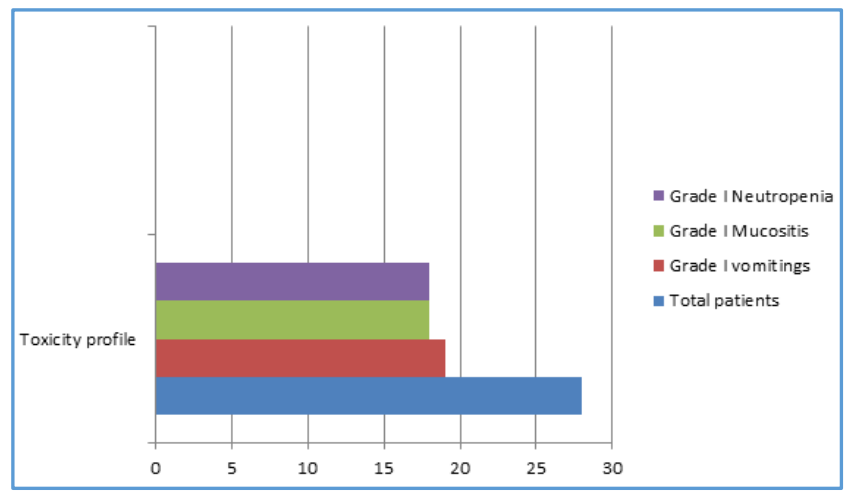

Fig. 3: Toxicity Profile

\section{DISCUSSION}

Gastric cancer is one of the common malignancies and carries high mortality in spite of existing treatment strategies. It is the $4^{\text {th }}$ most common malignancy and $2^{\text {nd }}$ leading cause of cancer related deaths in the world. However, in India, except in certain pockets, Gastric cancer is low in incidence. It is seen more commonly in south Indians especially more in males, the possible reasons can be attributed to higher consumption of spices and higher rate of tobacco and alcohol addictions. Highest incidence surprisingly is noted in Mizoram state of India; the reasons are as noted above and in addition there could be unknown genetic factors. In Kashmir, no correlation between Gastric cancer and Helicobacter pylori infection was evident. Again, the shift in incidence from distal cancers to proximal as seen globally is not evident in India.

There has been a recent decline in the incidence of gastric cancers worldwide. This trend; however, was not observed in India. Majority of cases seen in India are in advanced stages. Despite the recent decline in the incidence of stomach cancer, worldwide treatment remains a challenge for Oncologists, and the prognosis remains poor except in some countries. The explanations for these poor results are multifactorial. The lack of defined risk factors and specific symptoms and the relatively low incidence have contributed to the late stage at diagnosis and poor treatment outcome.12 The only proven curative treatment for gastric cancer is surgical resection of all gross and microscopic disease, nevertheless studies have shown that surgery alone is less than satisfactory with the 5year survival rate as low as 10-20\%.9 except in Japan where 5year survival is $40-45 \% .13$ Even after what is felt to be a curative gastrectomy, disease recurs in both regional and distant sites in the majority of patients. Role of extended node dissection has not been found to have survival benefit in randomised trials.

Because both local \& systemic relapses are common after resection of high risk gastric cancers (beyond serosa, node positive or both), adjuvant treatment is indicated for these patients. Our study shows that a combination of chemotherapy and radiotherapy offers reduced recurrence rates in high risk resected gastric cancers. Other studies in single institution studies have reported better survivals after chemo irradiation compared to chemotherapy alone.

Since our study was done by conventional method of radiation using Telecobalt machine, further studies employing latest conformal forms like IMRT in future trials can further reduce the morbidity. Future trials including more effective chemo drugs like Gemcitabine, Oxaliplatin and Docetaxel with added rescue factors may also improve local control rates.

\section{CONCLUSION}

Adjuvant Radiotherapy concurrently with Chemotherapy has shown benefit for all patients with high risk gastric cancer who underwent curative surgery. The toxicity profile was acceptable and manageable. In Indian setup patients, this study has shown that this protocol is tolerable with acceptable toxicity with reduction in locoregional recurrence rates. There is a need for randomised trial with large group of patients and further longterm followup to evaluate disease free survival and overall survival rates.

\section{REFERENCES}

1. Bobba R, Khan Y. Cancer in India-an overview. GOR 2003;5(4):93-6.

2. International agency for research on cancer: Cancer incidence and mortality worldwide. www.iarc.fr/en/mediacenter/iarcnews/2010/globocon 2008.php.

3. Parkin DM, Bray FI, Devesa SS. Cancer burden in the year 2000. The global picture. Eur J Cancer 2001;37(Suppl 8):S4-66.

4. International Agency For Cancer www.dep.iarc.fr/globocon.html.2000.

5. Pavithran K, Doval DC, Pandey KK. Gastric cancer in India. Gastric Cancer 2002;5(4):240-3.

6. Malhotra SL. Geographical distribution of gastrointestinal cancer in India with special reference to causation. Gut 1967;8(4):361-72.

7. Varghese C. Cancer prevention and control in India. National cancer registry programme, fifty years of cancer control in India page 48-59.

8. Dupont JB, Lee JR, Burton GR, et al. Adenocarcinoma of the stomach: review of 1,497 cases. Cancer 1978;41(3):941-7.

9. Gloeckler LA, Kosary CL, Hankey BF, et al. SEER cancer statistics review, 1973-1994. NIH publication No.97-2789, Department of health and human services, Bethesda: 1997.

10. Yoo CH, Noh SH, Shin DW, et al. Recurrence following curative resection for gastric carcinoma. Br J Surgery 2000;87(2):236-42. 
11. Macdonald JS, Beneditti N, Estes N. Post-operative combined chemotherapy and Radiotherapy improves Disease Free Survival (DFS) and Overall Survival (OS) in resected adenocarcinoma of the stomach and G.E junction: update of the results of intergroup study INT-0116 (SWOG 9008). ASCO, San Francisco: 2004.

12. Pisters PWT, Kelsen DP, Joel E. Tepper. Cancer of the stomach. In: Devita VT, Lawrence TS, Rosenberg SA. eds. Cancer principles and practice of oncology. $8^{\text {th }}$ edn. Philadelphia, USA: Lippincott Williams \& Wilkins 2008; P.1044.
13. Maruyama K, Sasako M, Kinnoshita T, et al. Surgical treatment for gastric cancer: the Japanese approach. Semin Oncol 1996;23(3):360-8. 